\title{
Improving the Motivation and the Classroom Climate of Secondary School Biology Students Using Problem-Based - Jigsaw Discussion (PBL-JD) Learning
}

\author{
Muhamad Hugerat ${ }^{1,2,3^{*}}$, Naji Kortam ${ }^{1}$, Fadda Kassom ${ }^{1}$, Shafea Algamal ${ }^{3}$, Sare Asli ${ }^{2,4}$ \\ 1 The Academic Arab College for Education in Israel, Haifa, ISRAEL \\ ${ }^{2}$ The Science Education Center, The Institute of Applied Research, The Galilee Society, Shefar-Am, ISRAEL and Evolution Institute \\ of Haifa University, Haifa, ISRAEL \\ ${ }^{3}$ Ministry of Education, Jerusalem, ISRAEL \\ ${ }^{4}$ Al-Qasemi Academic College, Baka El-Garbiah, ISRAEL
}

Received 12 May 2021 - Accepted 15 September 2021

\begin{abstract}
Classroom climate and motivation plays a major role in the teaching-learning process. In this study, we proposed a new teaching method (PBL-JD). "Problem-Based Learning" (PBL)-Jigsaw Discussion (JD) (PBL-JD) is a student-centered teaching methodology applied in science education; it ensures that the students are actively involved throughout the learning process. The main aim of this research was to examine the effect of the PBL-JD method on students' motivation to learn science and on the science classroom climate. The participants of this pre-test - post-test quasi-experimental research consisted of 204 tenth graders studying the blood circulation system. Ninety-eight students were assigned to the experimental group and 106 to the control group. The experimental group was taught using the PBL-JD method, whereas the control group used the traditional non-PBL method, i.e., lecture-based learning. Two questionnaires (pre and post) were distributed (one for evaluating motivation and another for evaluating the science classroom climate). Significant differences were found among the experimental group, who improved their motivation and their perception of the classroom climate.
\end{abstract}

Keywords: PBL-JD, classroom climate, motivation, high school, biology education

\section{INTRODUCTION}

\section{Problem-Based Learning (PBL)}

Many pedagogical theories have been developed and implemented in order to provide more efficient teaching, which takes into account the special needs of students and enables them to fully exploit their personal abilities. One of these methods is "Problem-Based Learning" (PBL). This method is derived from the theory of Constructivism, which stresses the active and critical construction of knowledge based on previous knowledge (Lapuz \& Fulgencio, 2020). PBL is a studentcentered method based on the principle of using problems as the starting point for acquiring new knowledge (Lambros, 2004). The learner copes with the problems, defines them, collects and acquires knowledge about them, and acquires skills and experience in problem solving (Nagarajan \& Overton, 2019; Overton \& Randles, 2015).

Akinoglu and Tandogan (2006) defined PBL as a process in which students take responsibility for their own learning and are able to make decisions. It is therefore important for students to be exposed to many real problems in their learning environment and to come up with appropriate solutions. PBL is an active, cooperative effort that takes place in small groups that promote student alertness and demonstrate their ability to solve problems, to learn how to learn, and to be able to apply that knowledge to solve real-life problems. The role of the teacher in this kind of learning is to assist and guide (Hmelo-Silver, 2004). Podges and Kommers (2013) as well as Siew and Mapeala (2016) showed that PBL enhances learners' confidence in their ability to solve substantive problems using critical thinking. Moreover, Siew et al. (2015) suggest that the PBL activities have a 


\section{Contribution to the literature}

- The study presents an innovative method for teaching science (PBL-JD), when we connect together, "Problem Based Learning" (PBL) and "Jigsaw Discussion" (JD).

- The study examines the contribution of implementation a PBL-JD strategy, as an alternative learning method, to raising students' motivation and improving the classroom climate when teaching and learning science.

- The PBL-JD method definitely can be recommended for use in teaching the sciences, since it makes learning more experiential and significant.

positive impact on fostering students' scientific creativity in science lessons. Hallinger and Bridges (2010) applied PBL to management education; consequently, students' learning outcomes were found to be better than those with ordinary learning approaches. Gallagher (2001) noted three key defining features of PBL instruction: (a) Unstructured problems in science teaching are interdisciplinary. Hence, learning begins and is framed as an interdisciplinary and unstructured problem. (b) the teacher serves as a metacognitive coach, and (c) the student is the primary stakeholder in the learning process. Rillero and Chen (2019) argued that PBL can integrate diverse subjects with meaningful experiences. Baran and Sozbilir (2017) In light of their findings, declared it very effective and productive to start using context- and problem-based learning (C-PBL) in teaching chemistry. Vasconcelos (2012) found that PBL methodology helps students develop group work collaboratively and learn from real environmental issues. Tarhan et al. (2008), Tarhan and Ayyıldız, (2015), also Sungur et al. (2006) who examined the effectiveness of PBL showed that PBL is very effective for formation of knowledge, influences student achievement, facility of formation of alternative perceptions as well as social skills.

Carrió et al. (2011) describe an experience in which PBL has been introduced as an interdisciplinary activity in the teaching of students in the bachelor degree of biology, with special attention on the analysis of contextualized complex problems. They conclude that the use of an interdisciplinary hybrid problem-based learning approach (H-PBL), in contrast to the lecturebased learning (LBL) traditional curriculum, has no deleterious effect on the recall of factual knowledge, while it may permit the simultaneous development of other professional skills, which could be more difficult to attain in traditional curricula based mainly on the lecture-based method.

Project-based learning practice in school, aligns what students learn with the needs of the modern workplace, making it a desirable goal for schools. The two most significant challenges are teamwork, and high-order thinking skill by students, and the difficulty that teachers and students experience in personalizing non-traditional teaching and learning roles. Other important challenges include demanding workloads for teachers and students, superficial gain of content knowledge, lack of clear application guidelines, lack of focus on identified learning outcomes, lack of skilled manpower that can lead to PBL and lack of adequate professional development for PBL training (Bell, 2010).

\section{Jigsaw Discussion (JD)}

Problem solving skills can be taught through cooperative learning allowing for each student to learn from the past experiences, knowledge, and understanding of peers (Winschel et al., 2015). Cooperative learning has become entrenched in the teaching-learning situation as an instructional strategy with great potential and impact. One of the cooperative learning strategies is the Jigsaw discussion (JD). JD provides a task structure to increase student learning. JD emphasizes peer learning by dividing the labor of learning among small groups of students. The jigsaw group arrangement allows students to help each other understand information about corresponding topics by apportioning the work of learning - each student in a small group is responsible for acquiring expertise about a different topic, theory, or reading, and sharing their expertise with others in the group. The jigsaw activity is organized by dividing a class into several groups and assigning each group a different, but linked, topic (Chang, 2009; Saputra et al., 2019). Cooperative learning through JD is an instructional strategy that is shown to improve students' problem-solving ability (Winschel et al., 2015). Cooper et al. (2008) found that students who participated in collaborative work has developed improved problem-solving Strategies that continued to run while working separately. Baken et al. (2020) found the use of team-based learning approaches such as the Jigsaw method and specifically show that undergraduate biology laboratory courses can be improved by implementing such activities in lieu of a clear experimental approach to laboratory courses.

The jigsaw cooperative model has the following procedures (1) Students form a home group consisting of 4-6 people; (2) The teacher explains the outline of the materials to be discussed; (3) Each member in the home group has responsibility for studying more specific materials; (4) Members who acquire the same materials come together with expert groups to discuss specific materials; (5) After the discussion, the group members of 
the expert group return to the home group to explain to the group of experts the materials they have obtained; (6) At the end of the study, test questions are given that must be performed individually (Slavin, 1995; Saputra, 2019).

For the jigsaw discussion group method, the teacher may take each student's personal score and offer it to the rest of the small group. Each member of the small group will receive this average in addition to their personal score. This helps ensure that all students work collaboratively to teach the material and hold each other accountable. The jigsaw discussion can be an effective collaborative learning strategy. Although the jigsaw discussion task takes time in class, the instructor does not have to spend much time on lectures on the subject. If planned well, the overall time commitment to using the puzzle technique during the lesson can be similar to lectures on the subject (Saputra, 2019; Slavin, 1995).

In the current research we proposed a new teaching method (PBL-JD), when we connect together, "ProblemBased Learning" (PBL) and "Jigsaw Discussion" (JD).

\section{PBL-JD}

PBL using a jigsaw discussion (PBL-JD) is a highly immersive student-centered approach that allows students extended time, often over the entire semester, to investigate an authentic problem or question while developing knowledge and skills. The project culminates in sharing their information with a "realworld" audience through a final presentation, video, or report for example. Using this student-centered approach, each student studies the topic materials. Then, they work in groups to share ideas, debate different views and teach each other (Chang, 2009; Choe \& Drennan, 2001). When students face a complex and complicated problem and put them in groups to share knowledge, they practice and expand problem-solving skills. The collaboration that occurs during the PBL process also provides students with the opportunity to share knowledge, experiences, identify knowledge deficits, reconcile multiple perspectives, develop social skills, and distribute the cognitive load (Hmelo-Silver et al., 2007).

Biology, as one of the science discipline, deals with the study of a living organism. By learning biology, the individual studies him or herself and another organism as living beings, Interaction between them and the nonliving beings. Such knowledge is used to improve the life of the individual. The human body is a very complex system, because each of its subsystems is a complex system in its own right, including the blood circulation system, Which the current study focused on. The human body subject according to the Ministry of Education in Israel, Culture and Sport (2016) represents the level of the whole multicellular organism because it is relevant to the student, allows for awareness of health and illness and stimulates interest, curiosity and enthusiasm. The blood circulation system is studied within the human body subject and assigned to it for 16 hours. Ben-Zvi Assaraf et al. (2013) argue that understanding the nature of the human body is a very challenging issue for students. This article presents research that spans one school year. The researchers examined the effect of the PBL-JD method on the blood circulation system, especially diseases related to this system, where students are at the center, researchers, arguing, consulting, debating, collaborating, and all in guiding of the teacher to motivate students' science learning and perception of the classroom environment.

\section{The Science Classroom Climate}

Classroom climate refers to elements of the class atmosphere related to the personal, social, academic, and cultural features of students in a certain learning environment and to the way in which they perceive what occurs in it as a result of their interactions with each other, the teacher, and the material to be learned (Fraser, 2012; Kearney et al., 2016). The classroom climate is very important for promoting positive learning and for stimulating students who want to learn (Lerdpornkulrat et al., 2018). Studies have shown that a positive climate enhances students' self-esteem and promotes academic achievement. Classes in which the climate is characterized by competitiveness, hostility, and alienation as well as anxiety and discomfort make it difficult for many students to fully develop academically. By contrast, classes in which mutual support exists among students as well as between the students and the teacher foster the development of selfesteem, involvement, and a sense of belonging (Hugerat 2016; Lewis et al., 1996).

When the classroom climate is studied, the teaching method must be taken into account, because one of the ways to change and improve the school system is by improving the classroom climate, which can contribute to greater interest and motivation among students, and improved academic achievement (Broussard \& Garrison, 2004). Cooperative learning is one of the prominent features of PBL. This method creates a classroom culture of cooperation and requires skills such as teamwork, listening to others, cooperation, appreciation, and more. Such a climate encourages students to respect and accept the responses and views of others, and it creates a culture of cooperative effort (Kolodner et al., 2003). Salter (2003) stated that cooperative learning has a very positive effect on the classroom climate and on academic achievement, and that it also improves the learning process and makes it more efficient. Hofstein et al. (2000) showed that PBL in the sciences improves both students' attitudes towards science and the classroom climate.

Hofstein et al. (2001), and Hugerat (2016) found that education in which research aspects are included creates 
a unique learning environment that differs from a classroom environment where other teaching methods are used. Research-oriented learning increases student involvement in the learning process and helps students structure and apply their knowledge about scientific concepts and processes. Such a learning environment is an efficient and authentic way for students to develop and to create their own knowledge base and understanding of scientific ideas and concepts. Furthermore, Dkeidek et al. (2012) confirmed that students who discuss the work that they do in small groups consequently develop good communication skills among themselves and with their teacher. Each member of the group participates in the discussion and this has a direct, positive effect on the learning environment. Problem-based learning, which generally takes place in small groups, can thus make a positive contribution in this respect as well. Ferreira and Trudel (2012) found that use of PBL resulted in a significant improvement in student attitudes toward science, problem-solving skills, as well as positive views of the learning environment. Its use also facilitated the development of a sense of community in the classroom.

A number of researchers (Ball, 1977; Elliot \& Thrash, 2001) have argued that motivation is greatly affected by the psychological characteristics of students' personalities. However, since motivation style is a type of interaction between the student and the learning environment, the teacher is responsible for ensuring that this environment will promote motivation to learn among students. The classroom climate contributes to greater interest and motivation and to improved achievements (Broussard \& Garrison 2004). Anderson et al. (2004) showed that some aspects of the classroom climate are significantly related to motivation. A positive classroom climate has been linked to positive student outcomes, such as promoting student motivation (Ellis 2004). Ferreira and Trudel (2012) found a significant improvement in student attitudes toward science, problem-solving skills, as well as more positive views of the learning environment. The use of PBL also facilitated the development of a sense of community in the classroom.

\section{Science Learning Motivation}

Motivation to learn science plays an important role in the persistence, achievement, and career aspirations of students studying science, technology, engineering, and math (STEM) (Bae \& DeBusk-Lane, 2018; Covert et al., 2019).

Motivation is a state of mind that motivates a person to work in a certain way to achieve the desired goals. It is a force that drives a person to work with high commitment and focus. Elliot and Thrash (2001) defined motivation as a theoretical structure that we use to explain why people do what they do. It is a process that explains how a person responds to a need or a general desire and puts into motion a series of efficient actions in order to meet that need. Psychologists define motivation processes as processes that encourage, guide, regulate, or stop a certain behavior (Ball, 1977). Glynn et al. (2011) outlined four related components of an individual's motivation to learn science: intrinsic motivation, selfdetermination, self-efficacy, and extrinsic motivation. As researchers (Covert et al., 2019; Pintrich et al., 1993; Wolters \& Rosenthal, 2000) have suggested, motivation plays an important role in science teaching and learning, students' success in science topics, their conceptual changes, critical thinking, and the development of science skills and capabilities.

The concept of motivation has received considerable attention in both psychology and education; it was considered as one of the most important theoretical factors in understanding human behavior (Beck, 2000). Motivation affects student learning (Ormrod, 2000) and plays an important role in directing behavior towards a certain goal, increasing the effort and energy towards a goal, increasing the initiative and perseverance of an activity, and improves individual performance. Instructional materials that are challenging give students some choices and they promote students' perceived autonomy; students' self-determination can positively affect their motivation (Hidi \& Harackiewicz, 2000). Podges and Kommers (2013) showed that motivation to learn improved when learners participated in PBL activities; the choice of an appropriate learning strategy thus enhances learners' motivation.

The current research examined the contribution of implementation a PBL-JD strategy, as an alternative learning method, to raising students' motivation and improving the classroom climate when teaching and learning science.

\section{RESEARCH METHODOLOGY}

\section{The Student Sample}

Science educators believe that a teacher must mix the groups so that students of all levels are represented in each group. If given a choice, students prefer to learning in homogeneous groups of their peers and friends, but they also appreciate getting to know and learn from other members of the classroom. Heterogeneous groupings are ideal for helping struggling students (Schullery \& Schullery, 2006).

The sample was taken from two different high schools in the northern district of Israel. Eight heterogeneous $10^{\text {th }}$ grade classes were chosen in which biology was taught, four for the experimental group $(\mathrm{N}=106)$ and four for the control group ( $\mathrm{N}=98)(48 \%$ males and $52 \%$ females). In each school, there were two experimental classes and two control classes. The experimental classes were taught biology through the 
PBL-JD method and the control classes were taught using the traditional method (e.g., routine, conventional, and lecture-based learning). A description of these learning methods is provided later. The experimental and control classes were randomly divided. We selected these groups because the average cumulative grades achieved by students in both groups before the experiment were statistically similar. The students were selected using a random sampling technique.

The scientific backgrounds of the students in the control and the experimental groups were similar. Other factors that can influence students' motivation and perception are the students' sociocultural status, the parents' educational backgrounds, the economic status of their families as well as their social lives; the families were generally in the middle class. Instructions for both groups were given with the same number of lessons.

\section{Data Collection and Instruments}

Data were collected through quantitative and qualitative tools (a mixed method). The quantitative part consisted of two questionnaires. The first questionnaire examined students' perception of the science classroom climate. The questionnaire consisted of 32 items; it was developed by Zedan (2008). In the present study we used the same version that Hugerat (2016) used. Cronbach's alpha was calculated and found to be 0.899 . The second questionnaire, which examined students' motivation, consisted of 26 items (Shawn et al., 2009). Cronbach's alpha was calculated and found to be 0.823 . Both questionnaires were distributed to the students in the experimental and control classes both before and after the planned topic had been taught. The lessons focused on human biology, according to the Israel Ministry of Education, Culture, and Sport 2005 syllabus for five study units in biology. Each questionnaire was distributed separately for an entire lesson (lasting 45 minutes). The pre- and post-questionnaires were identical. The participating students were asked to rate their interest on a five-point Likert-type scale in both questionnaires. All respondents were informed about the anonymity of the research. The participants were informed that they were under no obligation to participate in the study and that they were free to withdraw from it at any time, with no negative consequences. The impact of PBL-JD on students' motivation and on their perception of the classroom climate were also assessed based on feedback from those students involved in PBL-JD (the experimental group).

After the intervention, individual interviews were carried out. Seven learners from the experimental group were interviewed in order to determine their experiences (four females and three males). The aim of the interview was to determine students' opinions about PBL-JD and to elicit information from the students and cross-check it with the quantitative data in order to improve its reliability. Each interview lasted about 25 minutes. The interviews were recorded and transcribed.

\section{Research Procedure}

The research continued for a full term (for thirteen weeks) and included four stages:

1. A pre-questionnaire transfers (Distribution of the questionnaires of the classroom climate and of the motivation to all the participating students before the start of the project): Before the learning stage, students in both the experimental and the control group were given the classroom climate and the motivation questionnaires.

2. The method of intervention: The students in the experimental group were informed by their teacher about PBL-JD (Hadkaew et al., 2008; Lee et al., 2015). They were divided into groups of between four and five students (home groups). Each group studied one kind of illness associated with the blood circulation system: hypertension, hypotension, diabetes, LDL/HDL hypercholesterolemia, anemia, heart attacks, obesity, smoking, and more. The students were asked to characterize the illness in order to better understand its complexity. Each group identified and defined the illness at the problem-presentation stage and then formulated questions that needed to be answered in order to understand and solve the problem, for example, "What causes the disease?", "What facts are associated with it?", "Who is the risk group? and what are their characteristics?", "What are the symptoms of the disease?" "How can it be cured?", and "What sources of information are available?". Group members sought information to resolve the problem by assigning responsibilities to each group member to learn more specific sub-materials. At this stage, students used a variety of information sources, searched in libraries, and used the internet and every other source that could provide them with valid and reliable answers. Each group's research involved the use of information processing and organizational skills. In the course of the learning process, the students should build up their knowledge and their concepts in those domains relevant to the disease and they also should acquire general thinking skills. The next step was that the group members gathered with other group members who got the same sub materials (expert group). At this step, the students set up an expert group to seek a great amount of specific information in order to solve the problem of the given case study (the disease) as previously assigned in the home group. The teacher instructed students to search for some information from a variety of sources, so that the students' knowledge of the related topics could vastly increase. Next, each student returned to the home group respectively in order to hold a discussion in order to solve the assigned case study problems by using the information gained from the expert group. In this activity, the students shared each other their point of 
Table 1. Comparison of classroom climate perception and level of motivation among students in both groups before the intervention program

\begin{tabular}{|c|c|c|c|c|c|}
\hline & Group & $\mathrm{N}$ & Mean & SD & $\mathrm{T}$ \\
\hline \multirow[t]{2}{*}{ Classroom climate } & Control & 98 & 3.28 & 0.42 & \multirow{2}{*}{$1.203-$} \\
\hline & Experimental & 106 & 3.43 & 0.58 & \\
\hline Motivation & $\begin{array}{l}\text { Control } \\
\text { Experimental }\end{array}$ & $\begin{array}{c}98 \\
106\end{array}$ & $\begin{array}{l}3.73 \\
3.80\end{array}$ & $\begin{array}{l}0.65 \\
0.52\end{array}$ & -0.822 \\
\hline
\end{tabular}

Table 2. Comparison of the classroom climate perception and the level of motivation among the students of the experimental group $(\mathrm{N}=106)$ before and after the intervention program

\begin{tabular}{llccc}
\hline & Stage & Mean & SD & T \\
\hline Classroom climate & pre & 3.43 & 0.58 & \multirow{2}{*}{$-3.427^{* *}$} \\
& post & 3.87 & 0.67 & \multirow{2}{*}{$-3.220^{* *}$} \\
\hline Motivation & pre & 3.80 & 0.52 & 0.57 \\
& post & 4.05 & 0.05 & \\
\hline
\end{tabular}

${ }^{* *} \mathrm{p}<0.01$

view while dealing with the problem-solving activity. After having collected the needed information, they were asked to present the most suitable solution and to defend their choice. The groups worked on their respective topics for three months, after which each group handed in a portfolio and presented its work before the class. The final stage - the teacher assigned quiz or evaluation to each student. By contrast, the control group continued to learn human biology using the conventional method, based on frontal teaching, the standard textbook, and practiced by answering questions, usually quite simple, which appear at the end of each chapter.

3. Post-questionnaire transfers: At the end of the intervention process, the students were given postclassroom climate and motivation questionnaires.

4. Semi-structured interviews were held with the students.

\section{Data Analysis}

Descriptive statistics (mean and standard deviations) and inferential statistics (t-test) were utilized from SPSS version 22. Items with a positive meaning were coded on a Likert scale from 1 (absolutely disagree) to 5 (absolutely agree); items with a negative meaning were reversely coded. A lower score in the questionnaire indicated negative attitudes; a higher score indicated positive attitudes. The differences between the motivation and the classroom learning for the experimental and the control groups, were analyzed using independent samples t-test $(p<.001)$. In addition, responses from semi-structured interviews from the experimental and control groups were analyzed thematically to identify and evaluate students' experiences in their biology lessons. The audio-recorded data were transcribed verbatim and transcripts were analyzed using open, axial, and selective coding.

\section{FINDINGS}

\section{Quantitative}

To ensure that the two groups emerge from an equal point in terms of classroom climate and motivation, the difference between the experimental group and the control group was examined before the intervention program. The findings are presented in Table 1.

The findings in Table 1 indicate a non-significant difference in the perception of the classroom climate between the students of the experimental group and the students of the control group before the intervention program. It was also found that there is no significant difference between the students of the two groups in the level of motivation. If so, it can be stated that both groups came out of the same point in terms of the perception of the classroom climate and the level of motivation.

Also, a t-test was performed for differences in the experimental group students between pre and post the intervention. The findings are presented in Table 2.

The findings in Table 2 indicate a significant difference in the classroom climate by the experimental students group before the intervention program compared to their perception after it $(t=-3.427, p<0.01)$. This indicates that there has been a significant improvement in the perception of the classroom climate by the students as a result of their participation in the intervention program. In addition, the motivation also found that there was a significant difference between the experimental group students before the intervention program and after it $(\mathrm{t}=-3.220, \mathrm{p}<0.01)$. This indicates that there has been a significant improvement in the level of motivation of the experimental group students as a result of their participation in the intervention program.

In order to answer the research question, an independent samples t-test was conducted to determine the differences between the students in the experimental group (who studied biology using the PBL-JD method) and those in the control group (who studied biology 
Table 3. Comparison of the classroom climate and motivation among students in the experimental and the control groups

\begin{tabular}{llcccc}
\hline & Group & $\mathrm{N}$ & Mean & SD & T \\
\hline \multirow{2}{*}{ Classroom climate } & Control & 98 & 3.23 & 0.50 & \multirow{2}{*}{$-7.128^{* * *}$} \\
& Experimental & 106 & 3.87 & 0.67 & 0.73 \\
\hline \multirow{2}{*}{ Motivation } & Control & 98 & 3.68 & 0.57 & \multirow{2}{*}{$-3.704^{* * *}$} \\
& Experimental & 106 & 4.05 & 05 \\
\hline
\end{tabular}

*** $\mathrm{p}<.001$

using the traditional method). The results are presented in Table 3.

The results presented above show a statistically significant difference $(t=-7.128, p<.001)$ in the perception of the classroom climate between the students in the experimental and in the control groups. The mean for classroom climate perception among the students in the experimental group $(\mathrm{M}=3.87, \mathrm{SD}=0.67)$ was higher than that for the students in the control group $(\mathrm{M}=3.23$, $\mathrm{SD}=0.50)$. In other words, the perceived classroom climate improved for the students in the experimental group, who participated in the intervention program (the PBL-JD method), in comparison with the students in the control group (the non- PBL-JD method). Furthermore, also with respect to motivation level, a statistically significant difference $(t=-3.704, p<0.001)$ was found between the two groups. The motivation level in the experimental group was higher $(\mathrm{M}=4.05, \mathrm{SD}=0.57)$ than that in the control group $(\mathrm{M}=3.68, \mathrm{SD}=0.73)$. In other words, the motivation improved among the students in the experimental group, in comparison with the students in the control group. To conclude, the intervention in the experimental classes clearly promoted and improved the students' perception of the classroom climate with respect to learning science, regarding their level of motivation for learning, in contrast to the standard, traditional teaching method.

\section{Interviews with Students}

In addition to the quantitative data produced by the questionnaires, a semi-structured interview was conducted with students. Four themes were identified, which are as follows: 1) Satisfaction and enjoyment, 2) Interest in biology, 3) motivation, and 4) Support and encouragement. The themes are presented in Table 4.

To conclude, the answers show that learning human biology using the PBL-JD method had a significant, positive effect on the students. These findings are consistent with the claim that students enjoyed and benefited from PBL-JD. The students appear to have become more active and independent learners, highly motivated, and had a positive and challenging classroom climate. However, the less expected results were related to the students' difficulties in applying the PBL-JD; these

Table 4. The reason themes discovered in an interview with the experimental group

$\begin{array}{ll}\text { Theme } & \text { Quotes from } \\ \text { Students' responses }\end{array}$

Satisfaction and Learner 1: "The effect was very positive. I loved the subject and the method. For the first time I understand enjoyment what independent learning is".

Learner 2: “The teaching method was interesting, innovative, and challenging. It was connected to my daily life".

Learner 3: "The PBL-JD method has a positive effect on students".

Learner 4: "Most of the time I was bored with the biology lessons. However, we have enjoyed this method. I hope to continue to apply it to other topics".

Interest in Learner 1: "This method showed me why biology is a research subject and not just facts and information". biology Learner 2: "I found out that biology is a broad subject, full of knowledge, but that it also requires high-order thinking skills".

Learner 3: "Biology has become a more attractive and interesting subject".

Learner 4: "I used to think biology is similar to history, which means a lot of text. No studies and researchers are seen. My opinion about biology now and its status have greatly improved".

Motivation Learner 1: "This method had a positive influence on the classroom learning climate. I want to learn more by this method".

Learner 2: "The learning environment in which biology classes are held now respects students and challenges them more".

Learner 3: "Thanks to this method, I have the desire and the motivation to continue to take an independent interest in the subject taught in the classroom".

Learner 4: "I felt enthusiastic about the method and it improved of my self-confidence, which was expressed most by the initiatives I offered to the group".

Support and Learner 1: "The teacher support was significant and it spurred us to continue to complete the task". encouragement Learner 2: "Our teacher, who is the sole authority during the lessons, was very supportive and guided us wonderfully".

Learner 3: "Teacher support and guidance was just fine. Sometimes we were afraid to ask too much".

Learner 4: "For a student like me who is shy and with low self-confidence, it was very interesting for me to collaborate with my colleagues and also initiate meetings with the teacher". 
difficulties included managing time, the increased noise and discipline in the classroom, as well as collaboration with group members and the division of responsibility between them. Some participants indicated, also, that they did not trust the ability of their peers to teach them properly.

At the same time, interviews were conducted with students of the control group. The findings obtained showed on that most students indicated that their teachers teach in the traditional frontal method. Teaching is done through the books, exercises at the end of each chapter, experiments as required and a closed and "predictable" examination. Most lessons are for the purpose of imparting knowledge. In most cases the lessons are boring. Students also noted that their teachers tend to involve and share them during lessons, but not sufficiently.

\section{DISCUSSION}

The research examined the motivation level of students in the experimental and the control groups and found that it was significantly higher among the experimental group, apparently due to their participation in the intervention program. The findings showed that the intervention program in which students in the experimental group learned topics in biology using the PBL-JD method experienced an increase in motivation. These findings are consistent with those of other researchers, e.g., Winschel et al. (2015) in their study, they employed cooperative learning as an instructional approach to facilitate student development of spectroscopy problem solving skills. Coupled with attitude surveys, which were used to gauge students' perceptions of the activities, these results suggest that students found the discussions to be a useful source for learning spectroscopy. Tosun and Taskensenligil (2012), also demonstrated that the PBL method had a positive effect on three dimensions: the achievement of a determined aim, enhancement of the value of the learned subject, and self-efficiency. These three dimensions were considered the main products in evaluating the motivation. Podges and Kommers (2013), also found an increase in the level of motivation to study the subject among students who had learned using the PBL method. The findings in the study's qualitative part support those in the quantitative part. Many studies (e.g., Lepper et al., 2005) that examined the motivation levels of students who learned science in primary school found that this method contributed to understanding the subject matter. In addition, an analysis of the results of the research of Liu et al. (2011) showed that students significantly increased their knowledge of science from pretest to posttest. After using the PBL method, they were motivated and enjoyed the experience, and a significant positive relationship was found between students' motivation scores and their science knowledge posttest scores. In contrast to the students' increasing motivation in biology, this result is not in agreement with the research of Baran and Sozbilir (2017), who found that the students' attitudes and motivation to learn remained unchanged before and after the PBL intervention. The authors claimed that this is understandable, since both motivation and attitudes are affective behaviors, which require long-time treatment in order to see a significant lasting effect. However, there is contrasting evidence indicating that PBL practices have positive effects on motivation (Klegeris \& Hurren, 2011).

In comparing the classroom climate in science among students who learned using the PBL-JD method and those who learned using the traditional method, the findings show that the former reported a more positive attitude. The qualitative part supports this, as shown by the following statements by two students: "This teaching method had a positive effect on the learning climate in the classroom ... the class was noisy in a positive sense, and the discussion was profound and interesting". "Biology for me became more meaningful, more scientific, and challenging. The cooperation among students was fruitful". Thus, PBL-JD improves the school climate - PBL-JD brings about the creation of more intensive, tighter, and more significant teacher-student, teacher-teacher, and student-student relations, promotes personal attention and a culture of dialogue in the classroom and positively affects the students' sense of well-being in school. It enables more students to express themselves and encourages a honest and frank dialogue among the participants in the learning process. The findings of the present study are similar to those of Senocak et al. (2007), who also showed that there was a statistically significant difference between the experimental and the control groups in their attitude toward chemistry and that the significant effect of the PBL appears to lie in the students' satisfaction with the learning environment. These authors found that the PBL approach is viewed positively by learners, who describe it as enjoyable, interactive, relevant, practical, and holistic. Uzun et al. (2020) reached a similar conclusion. They concluded that the students were generally satisfied with the problem-based learning practices. Our findings are also in line with those of De Witte and Rogge (2016), who tested the effectiveness of PBL. Their findings indicate PBL's significant positive effect on student achievements, a significant positive effect on motivation, and a significant positive effect on the classroom atmosphere.

Several studies have been conducted on the impact of PBL on student motivation and the classroom climate. In these studies, a comparison was made between PBL students and students in a more traditional setting (where learning was based primarily on lectures). Some studies have indicated that PBL students score higher in several motivational aspects (Luo, 2019; Sungur \& Tekkaya, 2006). In addition, other studies revealed that PBL improves the classroom climate. For example, 
Thakur et al. (2018) assessed students' perception while they learned $9^{\text {th }}$ grade biology through the PBL method. The study revealed that PBL makes learning an enjoyable experience by exploring new knowledge, increasing curiosity among the learners, linking previous knowledge, and creating interest.

\section{CONCLUSIONS AND IMPLICATIONS}

As in previous studies, the students in the present study also became active learners and showed great motivation to learn at various stages of the research. It was found that this method promoted independence and individual learning. In this study the teachers facilitated the learning process by guiding the students through the various stages of PBL-JD, by connecting them to the problem, building the structure, visiting and revising the problem, creating a product and presenting and evaluating the implementation. This method helps students develop self-reliance and promotes a community spirit within the classroom. It was concluded that the intervention program in which students in the experimental group learned about human body using the PBL-JD method brought about an improvement in their motivation to learn science, and an improvement in their perception of the classroom climate.

Thus, teaching biology using the PBL-JD method had a positive effect on the students. It made them like the subject, increased their motivation, and provided them with opportunities to perform actions such as locating and using information sources, analyzing, planning, and evaluating solutions, and acquiring cooperative-groupeffort skills. From the present study, it can be concluded that the PBL-JD method definitely can be recommended for use in teaching the sciences, since it makes learning more experiential and significant.

However, this study had some limitations: students, who will be a part of every new science teaching program make them act more preventative ways and perhaps inflate their self-reports of motivation and involvement. It might be possible that these gains were a function of students' expectations, the practice effects, or their tendency to be 'smart in testing'. They were aware to the purpose of the intervention and may have been motivated to give the 'right' answers. In addition, teachers do not easily change their teaching methods. PBL-JD demands more time and effort, and therefore, it arouses opposition among some teachers. In order to generalize the findings to a wider population, we must examine the recurrence of the findings in other countries and among students studying biology as a compulsory profession. However, because we have had a diverse student population, for example by residence (urban versus rural) and geographical (central versus periphery), heterogeneity may prove that our findings may be valid for another diverse population.
Author contributions: All authors have sufficiently contributed to the study, and agreed with the results and conclusions.

Funding: The study is supported by the Academic Arab college for education in Israel-Haifa and the Center for Science Education- the Galilee Society and European Union Peacebuilding Initiative (EUPI) project [project agreement ENI/2019/412-148].

Declaration of interest: No conflict of interest is declared by authors.

\section{REFERENCES}

Akinoglu, O., \& Tandogan, R. O. (2006). The effect of problem-based active learning in science education on students' academic achievement, attitude and concept learning. Eurasia Journal of Mathematics, Science and Technology Education, 3(1), 71-81. https:/ / doi.org/10.12973/ejmste/75375

Anderson, A., Hamilton, R. J., \& Hattie, J. (2004). Classroom climate and motivated behaviour in secondary schools. Learning Environments Research, 7(3), 211-225. https:/ / doi.org/10.1007/s10984-0043292-9

Bae, C. L., \& DeBusk-Lane, M. (2018). Motivation belief profiles in science: Links to classroom goal structures and achievement. Learning and Individual Differences, 67, 91-104. https://doi.org/10.1016/ j.lindif.2018.08.003

Baken, E. K., Adams, D. C., \& Rentz, M. S. (2020). Jigsaw method improves learning and retention for observation-based undergraduate biology laboratory activities. Journal of Biological Education, 1-6.

https:/ / doi.org/10.1080/00219266.2020.1796757

Ball, S. (1977). Motivation in education: Educational testing service. Academic Press.

Baran, M., \& Sozbilir, M. (2017). An application of Context-and Problem-Based Learning (C-PBL) into teaching thermodynamics. Research in Science Education, 48(4), 663-689. https:/ / doi.org/10.1007/ s11165-016-9583-1

Beck, R. C. (2000). Motivation: Theories and principles. Prentice Hall.

Bell, S. (2010). Project-based learning for the 21st century: Skills for the future. The Clearing House: A Journal of Educational Strategies, Issues and Ideas, 83(2), 39-43. https://doi.org/10.1080/00098650903505415

Ben-Zvi Assaraf, O., J. Dodick., \& Tripto, J. (2013). High school students' understanding of the human body system. Research in Science Education, 43(1), 33-56. https://doi.org/10.1007/s11165-011-9245-2

Broussard, S. C., \& Garrison, M. E. B. (2004). The relationship between classroom motivation and academic achievement in elementary-school-aged children. Family and Consumer Sciences Research Journal, 33(2), 106-120. https://doi.org/10.1177/ $1077727 \times 04269573$ 
Carrió, M., Larramona., P., Baños, J. E., \& Pérez, J. (2011). The effectiveness of the hybrid problem-based learning approach in the teaching of biology: A comparison with lecture-based learning. Journal of Biological Education, 45(4), 229-235. https: / / doi.org/10.1080/00219266.2010.546011

Cetin-Dindar, A. (2016). Student motivation in constructivist learning environment. EURASIA Journal of Mathematics, Science \& Technology Education, 12(2), 233-247. https://doi.org/10.12973 / eurasia.2016.1399a

Chang, C. C. (2009). Using jigsaw collaborative learning strategy in online discussion to foster a project based learning community on the web. International Journal of Instructional Media, 36(2), 221-233.

Choe, S. W. T., \& Drennan, P. M. (2001). Analyzing scientific literature using a jigsaw group activity: Piecing together student discussions on environmental research. Journal of College Science Teaching, 30(5), 328-330.

Cooper, M. M., Cox, C. T. Jr, Nammouz., M., Case, E., \& Stevens, R. (2008). An assessment of the effect of collaborative groups on students' problem-solving strategies and abilities. Journal of Chemical Education, 85(6), 866-872. https:/ / doi.org/10.1021/ ed085p866

Covert, H., Ilunga Tshiswaka, D., Ramkissoon, I., Sisskin, E., Lichtveld, M., \& Wickliffe, J. (2019). Assessing science motivation among high school students participating in a supplemental science programme: The emerging scholars environmental health sciences academy. International Journal of Science Education, 41(17), 2508-2523. https:/ / doi.org/10.1080/09500693.2019.1689308

De Witte, K., \& Rogge, N. (2016). Problem-based learning in secondary education: Evaluation by an experiment. Education Economics, 24(1), 58-82. https: / / doi.org/10.1080/09645292.2014.966061

Dkeidek, I., Mamlok-Naaman, R., \& Hofstein, A. (2012). Assessment of the laboratory learning environment in an inquiry-oriented chemistry laboratory in Arab and Jewish high schools in Israel. Learning Environments Research, 15(2), 141-169. https:/ / doi.org/10.1007/s10984-012-9109-3

Elliot, A. J., \& Thrash, T. M. (2001). Achievement goals and the hierarchical model of achievement motivation. Educational Psychology Review, 13(2), 139-156.

https:/ / doi.org/10.1023/A:1009057102306

Ellis, K. (2004). The impact of perceived teacher confirmation on receiver apprehension, motivation, and learning. Communication Education, 53(1), 1-20. https://doi.org/10.1080/03634520320 00135742
Ferreira, M. M., \& Trudel, A. R. (2012). The impact of Problem-Based Learning (PBL) on student attitudes toward science, problem-solving skills, and sense of community in the classroom. Journal of classroom interaction, 47(1) 23-30.

Fraser, B. (2012). Classroom learning environments: Retrospect, context, and prospect. In B. Fraser, K. Tobin, \& C. McRobbie (Eds.), Second international handbook of science education (pp. 1191-1239). Springer. https://doi.org/10.1007/978-1-40209041-7_79

Gallagher, S. A. (2001). But does it work? Testing the efficacy of problem-based learning: A review of the literature and research agenda for educators of the gifted. In N. Colangelo, \& S. G. Wallace (Eds.), Talent development: Proceedings from the 1998 Henry B. and Jocelyn Wallace National Research Symposium (pp. 179-204). Great Potential Press.

Glynn, S. W., Brickman, P., Armstrong, N., \& Taasoobshirazi, G. (2011). Science motivation questionnaire II: Validation with science majors and nonscience majors. Journal of Research in Science Teaching, 48(10), 1159-1176. https://doi.org/ 10.1002/tea.20442

Hadkaew, P., Wiwatanapataphee, B., \& Wu, Y. H. (2008). Project-based learning model for the study of blood flow in the human blood circulatory system. International Journal of Learning, 15(3), 195-202. https:/ / doi.org/10.18848/1447-9494/CGP/v15i03 /45686

Hallinger, P., \& Bridges, E. M. (2010). A problem-based approach for management education: Preparing managers for action. Springer.

Hidi, S., \& Harackiewicz, J. M. (2000). Motivating the academically unmotivated: A critical issue for the 21st century. Review of Educational Research, 70(2), 151-179. https:/ / doi.org/10.3102/00346543070002151

Hmelo-Silver, C. D. (2004). Problem-based learning: What and how do students learn? Educational Psychology Review, 16(3), 235-266. https://doi.org/ 10.1023/B:EDPR.0000034022.16470.f3

Hmelo-Silver, C. E., Duncan, R. G., \& Chinn, C. A. (2007). Scaffolding and achievement in problem-based and inquiry learning: A response to Kirschner, Sweller, \& Clark (2006). Educational Psychologist, 42(2), 99107. https:/ / doi.org/10.1080/00461520701263368

Hofstein, A., Kesner, M., \& Ben-Zvi, R. (2000). Student perceptions of industrial chemistry classroom learning environments. Learning Environments Research, 2(3), 291-306. https://doi.org/10.1023/ A:1009973908142

Hofstein, A., Levy-Nahum, T., \& Shore, R. (2001). Assessment of the learning environment of inquirytype laboratories in high school chemistry. Learning 
Environment Research, 4(2), 193-207. https:/ / doi.org/10.1023/A:1012467417645

Hugerat, M. (2016). How teaching science using projectbased learning strategies affects the classroom learning environment. Learning Environments Research, 19(3), 383-395. https://doi.org/10.1007/ s10984-016-9212-y

Kearney, W. S., Smith, P. A., \& Maika, S. (2016). Asking students their opinions of the learning environment: An empirical analysis of elementary classroom climate. Educational Psychology in Practice, 32(3), 310-320. https://doi.org/10.1080/ 02667363.2016 .1173015

Klegeris, A., \& Hurren, H. (2011). Impact of problembased learning in a large classroom setting: Student perception and problem-solving skills. Advances in Physiology Education, 35(4), 408-415. https:/ / doi.org/10.1152/advan.00046.2011

Kolodner, J. L., Camp, P. J., Crismond, D., Fasse, B., Gray, J., Holbrook, J., Puntambekar, S., \& Ryan, M. (2003). Problem-based learning meets case-based reasoning in the middle-school science classroom: Putting learning by design TM into practice. The Journal of the Learning Sciences, 12(4), 495-547. https:/ / doi.org/10.1207/S15327809JLS1204_2

Lambros, A. (2004). Problem based learning in middle and high school classrooms: A teacher's guide to implementation. Corwin Press.

Lapuz, A. M., \& Fulgencio, M. N. (2020). Improving the critical thinking skills of secondary school students using problem-based learning. International Journal of Academic Multidisciplinary Research, 4(1), 1-7.

Lee, S., Kang, E., \& Kim, H. B. (2015). Exploring the impact of students' learning approach on collaborative group modeling of blood circulation. Journal of Science Education and Technology, 24(2-3), 234-255. https://doi.org/10.1007/s10956-0149509-5

Lepper, M., Corpus, J., \& Iyenger, S. (2005). Intrinsic and extrinsic motivational orientations in the classroom: Age differences and academic correlates. Journal of Educational Psychology, 97(2), 184-196. https: / / doi.org/10.1037/0022-0663.97.2.184

Lerdpornkulrat, T., Koul, R., \& Poondej, C. (2018). Relationship between perceptions of classroom climate and institutional goal structures and student motivation, engagement and intention to persist in college. Journal of further and Higher Education, 42(1), 102-115. https:/ / doi.org/10.1080/ 0309877X.2016.1206855

Lewis, C., Schaps, E., \& Watson, M. (1996). The caring classroom's academic edge. Educational Leadership, 54(1), 15-21.

Liu, M., Horton, L., Olmanson, J., \& Toprac, P. (2011). A study of learning and motivation in a new media enriched environment for middle school science. Educational Technology Research and Development, 59(2), 249-265. https://doi.org/10.1007/s11423011-9192-7

Luo, Y. J. (2019). The influence of problem-based learning on learning effectiveness in student's of varying learning abilities within physical education. Innovations in Education and Teaching International, 56(1), 3-13. https://doi.org/10.1080/ 14703297.2017.1389288

Ministry of Education, Culture and Sport. (2005). Situation Report on a School, METSAV 2004. Office of the General Manager, Department of Evaluation and Measurement, Pedagogical Administration, Department of Primary Education (in Hebrew).

Ministry of Education, Culture and Sport. (2016). High school biology curriculum. Office of the General Manager, Department of Evaluation and Measurement, Pedagogical Administration, Department of Primary Education (in Hebrew).

Nagarajan, S., \& Overton, T. (2019). Promoting systems thinking using project-and problem-based learning. Journal of Chemical Education, 96(12), 2901-2909. https:/ / doi.org/10.1021/acs.jchemed.9b00358

Ormrod, J. E. (2000). Educational psychology (3 ${ }^{\text {rd }}$ Ed.) Merrill/Prentice Hall.

Overton, T., \& Randles, C. A. (2015). Beyond problembased learning: Using dynamic PBL in chemistry. Chemistry Education Research and Practice, 16(2), 251259. https:/ / doi.org/10.1039/C4RP00248B

Papert, S. (1991). Situating constructionism. In I. Harel, \& S. Papert (Eds.), Constructionism (pp. 1-11). Ablex.

Pintrich, P. R., Marx, R. W., \& Boyle, R. A. (1993). Beyond cold conceptual change: The role of motivational beliefs and classroom contextual factors in the process of conceptual change. Review of Educational Research, 63(2), 167-199. https://doi.org/10.3102/ 00346543063002167

Podges, M., \& Kommers, P. (2013). The effect of problem based learning on the attitude, motivation and reflection of students. Proceedings of the $2^{\text {nd }}$ biennial conference of the South African society for engineering education. Cape Town, 11-12 June.

Rillero, P., \& Chen, Y. C. (2019). The use of a digital problem-based learning module in science methods courses. Journal of Problem Based Learning in Higher Education, 7(1), 107-119.

Salter, D. W. (2003). Exploring the chilly classroom phenomenon as interaction between psychological and environmental types. Journal of college Student Development, 44(1), 110-121. https://doi.org/ $10.1353 /$ csd.2003.0009

Saputra, M. D., Joyoatmojo, S., Wardani, D. K., \& Sangka, K. B. (2019). Developing critical-thinking skills through the collaboration of jigsaw model with 
problem-based learning model. International Journal of Instruction, 12(1), 1077-1094. https:/ / doi.org/10.29333/iji.2019.12169a

Schullery, N. M., \& Schullery, S. E. (2006). Are heterogeneous or homogeneous groups more beneficial to students? Journal of Management Education, 30(4), 542-556. https:/ / doi.org/10.1177/ 1052562905277305

Senocak, E., Taskesenligil, Y., \& Sozbili, M. (2007). A study on teaching gases to prospective primary science teachers through problem-based learning. Research in Science Education, 37(3), 279-290. https:// doi.org/10.1007/s11165-006-9026-5

Shawn, M., Glynn, S. M., Taasoobshirazi, G., \& Brickman, P. (2009). Science motivation questionnaire: Construct validation with nonscience majors. Journal of Research in Science Teaching, 46(2), 127-146. https://doi.org/10.1002/ tea.20267

Siew, N. M., \& Mapeala, R. (2016). The effects of problem-based learning with thinking maps on fifth graders' science critical thinking. Journal of Baltic Science Education, 15(5), 602-616. https:// doi.org/10.33225/jbse/16.15.602

Siew, N. M., Chong, C. L., \& Lee, B. N. (2015). Fostering fifth graders' scientific creativity through problem based learning. Journal of Baltic Science Education, 14(5), 655-669. https:// doi.org/10.33225/jbse/ 15.14.655

Slavin, R. E. (1995). Cooperative learning: Theory, research, and practice $\left(2^{\text {nd }} \mathrm{Ed}.\right)$. Allyn \& Bacon.

Sungur, S., \& Tekkaya, C. (2006). Effects of problembased learning and traditional instruction on selfregulated learning. The Journal of Educational Research, 99(5), 307-320. https://doi.org/10.3200/ JOER.99.5.307-320

Sungur, S., Tekkaya, C., \& Geban, Ö. (2006). Improving achievement through problem-based learning. Journal of Biological Education, 40(4), 155-160. https:// doi.org/10.1080/00219266.2006.9656037

Tarhan, L., \& Ayy1ldı, Y. (2015). The views of undergraduates about problem-based learning applications in a biochemistry course. Journal of Biological Education, 49(2), 116-126. https:/ / doi.org/10.1080/00219266.2014.888364

Tarhan, L., Ayar-Kayali, H., Urek, R. O., \& Acar, B. (2008). Problem-based learning in 9th grade chemistry class: 'Intermolecular forces'. Research in Science Education, 38(3), 285-300. https:/ / doi.org/10.1007/s11165-007-9050-0

Thakur, P., Dutt, S., \& Chauhan, A. (2018). Learning biology through problem based learningperception of students. Journal of Educational Technology, 15(2), 44-54. https:// doi.org/10.26634/ jet.15.2.14303

Tosun, C., \& Taskesenligil, Y. (2012). The effect of problem-based learning on student motivation towards classes and on learning strategies. Journal of Turkish Science Education, 9(1), 104-121.

Uzun, A., Onur, A., \& Alabay, S. (2020). Students' views on database management systems course designed according to problem-based learning. International Journal of Evaluation and Research in Education, 9(1), 177-187. https:// doi.org/10.11591/ijere.v9i1.20501

Vasconcelos, C. (2012). Teaching environmental education through PBL: Evaluation of a teaching intervention program. Research in Science Education, 42(2), 219-232. https://doi.org/10.1007/s11165010-9192-3

Winschel, G. A., Everett, R. K., Coppola, B. P., Shultz, G. V., \& Lonn, S. (2015). Using jigsaw-style spectroscopy problem-solving to elucidate molecular structure through online cooperative learning. Journal of Chemical Education, 92(7), 11881193.

https:/ / doi.org/10.1021/acs.jchemed.5b00114

Wolters, C. A., \& Rosenthal, H. (2000). The relation between students' motivational beliefs and their use of motivational regulation strategies. International Journal of Educational Research, 33(7), 801-820. https:/ / doi.org/10.1016/S0883-0355(00)00051-3

Zedan, R. (2008). Classroom climate among students of Arab primary schools in Israel. Studies in the management of the organization, 30, 51-80. (In Hebrew).

\section{http://www.ejmste.com}

